\title{
Integrity of prokaryotic mRNA isolated from complex samples for in vivo bacterial transcriptome analysis
}

\author{
A.B. Ferreira-Machado ${ }^{1}$, M.C.R. Freitas ${ }^{1}$, G.R.Q. Saji ${ }^{2}$, A.B. Rezende $^{3}$, \\ P.E. Almeida ${ }^{4}$, D.E. Cesar ${ }^{4}$, J.A. Resende ${ }^{1}$, M.F. Nicólas ${ }^{2}$, V.L. Silva ${ }^{1}$ and \\ C.G. Diniz
}

${ }^{1}$ Departamento de Parasitologia, Microbiologia e Imunologia, Universidade Federal de Juiz de Fora, Juiz de Fora, MG, Brasil ${ }^{2}$ Laboratório Nacional de Computação Científica, Petrópolis, RJ, Brasil ${ }^{3}$ Departamento de Morfologia, Universidade Federal de Juiz de Fora, Juiz de Fora, MG, Brasil

${ }^{4}$ Departamento de Biologia, Universidade Federal de Juiz de Fora, Juiz de Fora, MG, Brasil

Corresponding author: C.G. Diniz

E-mail: claudio.diniz@ufjf.edu.br

Genet. Mol. Res. 14 (4): 14752-14759 (2015)

Received July 5, 2015

Accepted September 15, 2015

Published November 18, 2015

DOI http://dx.doi.org/10.4238/2015.November.18.40

\begin{abstract}
Even though several in vitro studies have focused on bacterial biology, the extent of such knowledge is not complete when considering an actual infection. As culture-independent microbiology methods such as high-throughput sequencing became available, important aspects of host-bacterium interactions will be elucidated. Based on microbiological relevance, we considered Bacteroides fragilis in a murine experimental infection as a model system to evaluate the in vivo bacterial transcriptome in host exudates. A disproportionate number of reads belonging to the host genome were retrieved in the first round of pyrosequencing, even after depletion of ribosomal RNA; the average number of reads related to the eukaryotic genome was
\end{abstract}


71.924-67.7\%, whereas prokaryotic reads represented 34.338-32.3\% in host exudates. Thus, different treatments were used to improve the prokaryotic RNA yield: i) centrifugation; ii) ultrasonic treatment; and iii) ultrasonic treatment followed by centrifugation. The latter treatment was found to be the most efficient in generating bacterial yields, as it resulted in a higher number of Bacteroides cells. However, the RNA extracted after this treatment was not of sufficient quality to be used in cDNA synthesis. Our results suggest that the methodology routinely used for RNA extraction in transcriptional analysis is not appropriate for in vivo studies in complex samples. Furthermore, the most efficient treatment for generating good bacterial cell yields was not suitable to retrieve high-quality RNA. Therefore, as an alternative methodological approach to enable in vivo studies on host-bacterium interactions, we advise increasing the sequencing depth despite the high costs.

Key words: Bacteroides fragilis; Experimental infection; In vivo studies; Host-bacterium interaction; RNA extraction

\section{INTRODUCTION}

Historically, clinical and scientific microbiology have been based on methodological approaches to understand the phenomena related to bacterial biology and host-bacterium interactions. Classical culture-dependent microscopy-based methods are widely employed to access bacterial morphology, and biochemical and physiological characteristics (Delsenya et al., 2010). However, these culture-dependent approaches do not allow direct microbe evaluation in actual infections (Passalacqua et al., 2009). In this regard, the extent of our knowledge on microbe biology during the course of infections remains unclear, leading to the need for prospective in vivo studies to elucidate the in vivo aspects of the host-bacterium interaction.

Recently, as culture-independent methods have become available, molecular tools such as high-throughput sequencing have been applied to clinical and scientific microbiology (Passalacqua et al., 2009; Delsenya et al., 2010). In this context, high-throughput sequencing is thought to be useful to evaluate the bacterial transcriptome during an actual infection representing a new generation of genome-wide gene expression measurements based on mRNA sequencing (RNA-seq) (Sîrbu et al., 2012). These approaches are especially useful when considering resident microbiota as these bacteria can be modulated by host physiology and by xenobiotics such as antimicrobial drugs (Diniz et al., 2003; dos Santos et al., 2010; de Souza Filho et al., 2012; Santos et al., 2012).

The Gram-negative anaerobic rod Bacteroides fragilis, which is member of the gut microbiota, remains one of the most important putative pathogens associated with endogenous infections (Wexler, 2007; Brook, 2010). Since 1984, B. fragilis strains associated with diarrheal disease in animals and young children have been recognized by their secretion of a 20-kDa enterotoxin named fragilisin (Myers et al., 1984, 1987). Furthermore, more recently enterotoxigenic $B$. fragilis has been associated with inflammatory bowel disease and the promotion of colon tumorigenesis (Prindiville et al., 2000; Toprak et al., 2006).

This study focused on the evaluation of a murine model for in vivo transcriptional 
analysis of $B$. fragilis. The rat tissue cage model (Lobo et al., 2013), which consists of intraperitoneal implantation of a perforated table tennis "ping-pong" ball, was used to establish an intraperitoneal abscess infection and bacteria for RNA-seq were recovered from drained exudative secretions.

\section{MATERIAL AND METHODS}

\section{Experimental infection model}

Male Wistar rats $(\mathrm{N}=24)$ weighing approximately $300 \mathrm{~g}$ from the Center for Reproductive Biology of Federal University of Juiz de Fora were used in these experiments. Four groups of 12 rats were utilized for technical and biological replicates. To generate the infection model, approximately $250-300$ small holes of $1.5 \mathrm{~mm}$ in diameter were drilled in 24 table tennis balls, and these were then soaked for $16 \mathrm{~h}$ in $2 \%$ hypochlorite, washed with distilled water, and sterilized by ethylene oxide. Each ball was surgically placed into the intraperitoneal cavity of an animal under anesthesia with ketamine/xylazine.

A period of 3 weeks was allowed for animal recovery, vascularization, and fluid accumulation in the tissue cage balls. After the healing period, the balls became encapsulated in connective tissue, developed a blood supply, and were filled with sterile exudate with the appearance of serum and with characteristics similar to those already described (Bamberger et al., 2002; Lobo et al., 2013). Furthermore, the encapsulated tissue cage balls were inoculated with $1.0 \mathrm{~mL} \mathrm{~B}$. fragilis ATCC 43859 (approximately $10^{8} \mathrm{CFU} / \mathrm{mL}$ ) in $0.85 \% \mathrm{NaCl}$. The $B$. fragilis cells used for inoculation were anaerobically grown in Brain Heart Infusion broth (Himedia Laboratories, Mumbai, India) supplemented with $0.5 \%$ yeast extract, $0.1 \%$ L-cysteine, $0.5 \%$ hemin, and $0.1 \%$ menadione (BHI-S) for $16 \mathrm{~h}$ at $37^{\circ} \mathrm{C}$.

The experimental infection model described in this study is shown in Figure 1. All of the procedures involving the use of animals were in agreement with the Ethical Principles in Animal Research and were approved by the Institutional Ethics Committee for Animal Research of the Federal University of Juiz de Fora (protocol No. 035/2010).

\section{Bacterial viable counts in the exudate}

The rats were anesthetized with intraperitoneal injection of ketamine/xilazine followed brachial plexus exsanguination. The tissue cage ball was removed and the $8.0 \mathrm{~mL}$ exudate aspirate 8 days post-infection to evaluate the bacterial survival and persistence. The CFU count was performed as follows: $1.0 \mathrm{~mL}$ exudate was serially diluted in sterile saline solution, and the dilutions were plated on Brain Heart Infusion supplemented with hemin $(5 \mathrm{mg} / \mathrm{mL})$, menadione $(1 \mathrm{mg} / \mathrm{mL})$ and L-cysteine $0.1 \%(\mathrm{w} / \mathrm{v})$ BHI-S and incubated under anaerobic conditions at $37^{\circ} \mathrm{C}$. Some plates were also incubated aerobically (controls) to assess any possible contamination from the abscess. Gram staining was also performed for quality control purposes and to visualize the $B$. fragilis cells in the aspirated exudates (Figure 1e).

\section{Bacterium cell distribution in the tissue cage exudates and interaction with host leukocytes}

To visualize the $B$. fragilis cells in the tissue cage exudates and their interactions with 
host leukocytes, exudate samples were recovered as previously described both before and after experimental infection, and diluted in Turk solution $(0.01 \%$ crystal violet in $2 \%$ acetic acid solution) to lyse the red blood cells.

Eukaryotic cells were counted in a Neubauer chamber. A total of $1 \times 10^{5}$ cells from the exudates were smeared onto a slide using a cytocentrifuge (Cytospin, Thermo Fisher Scientific, Waltham, MA, USA) at $140 \mathrm{~g}$ for $10 \mathrm{~min}$ and then stained with May-GrünwaldGiemsa solution to analyze the leukocytes before experimental infection and the leukocytebacterium interactions after infection. Images were acquired using a Panoramic Slide Scan (3DHISTECH, Budapest, Hungary) equipped with a 20X objective. Cell viability was assessed using the Trypan blue exclusion method at the end of the experiment and was found to be greater than $90 \%$.

To analyze the CFUs of internalized bacteria, $10^{6}$ cells $/ \mathrm{mL}$ were centrifuged twice at $1500 \mathrm{rpm}$ for $10 \mathrm{~min}$ in an antibiotic solution ( $1 \mathrm{mg} / \mathrm{mL}$ ampicillin/sulbactam). The cells were lysed with $1 \mathrm{~mL} 0.1 \%$ saponin, and $10 \mu \mathrm{L}$ bacteria-containing suspensions were streaked onto BHI-S plates, which were anaerobically incubated at $37^{\circ} \mathrm{C}$ for $48 \mathrm{~h}$.

\section{Optimization of prokaryotic cell yields}

To increase the number of planktonic bacterial cells for RNA extraction obtained from the drained exudates, three different treatments were evaluated: i) centrifugation at $500 \mathrm{rpm}$ for $10 \mathrm{~min}$ in a serological table centrifuge; ii) ultrasonic treatment by three sonication pulses $(110.7 \mu \mathrm{m}, 60 \mathrm{~s})$ in an ice bath (Vibra Cell VCX 130PB, Sonics \& Materials Inc., Newtown, CT, USA); and iii) ultrasonic treatment by three sonication pulses $(110.7 \mu \mathrm{m}, 60 \mathrm{~s})$ in an ice bath followed by centrifugation at $500 \mathrm{rpm}$ for $10 \mathrm{~min}$ in a serological table centrifuge.

Following the different treatments, fluorescence in situ hybridization (FISH) was used to verify the best treatment for yielding prokaryotic cells leading to high content of bacterial RNA in the final RNA isolate. Aliquots of $0.3 \mathrm{~mL}$ for each treatment were filtered through $0.22-\mu \mathrm{m}$ polycarbonate filters (Nuclepore Whatman, GE Healthcare, Little Chalfont, UK) and stored at $4{ }^{\circ} \mathrm{C}$ until analysis by FISH. To determine the $B$. fragilis concentration after each treatment by FISH, a Cy3 fluorochrome-labeled Bac 303 probe (5'-CCA ATG TGG GGG ACC TT-3') was used as previously described (Manz et al., 1996). Direct counting at 1000X magnification was performed using an epifluorescence microscope (Olympus BX-60, Tokyo, Japan) equipped with the following filters: Chroma U-N41007, U-MWU2, U-MWB2, and UMWG2. Measurements were performed in triplicate.

\section{Total RNA extraction, cDNA synthesis, and pyrosequencing}

The total RNA from $1.0 \mathrm{~mL}$ drawn exudate was extracted using the RNeasy mini kit (Qiagen, Venlo, the Netherlands) according to manufacturer protocols. Furthermore, the MicrobEnrich kit (Ambion, Austin, TX, USA) was used to deplete the eukaryotic and prokaryotic ribosomal RNA. The total RNA quality was evaluated through on-chip microfluidic electrophoresis (Prokaryote Total RNA Pico kit, Bioanalyzer Instruments 2100, Agilent Technologies, Santa Clara, CA, USA). The RNA extracts with RNA integrity number (RIN) $>8$ were considered to be of sequencing quality and cDNA libraries were then constructed using the cDNA Rapid Library Preparation Method (Roche Diagnostics, Roswell, GA, USA), and subjected to pyrosequencing using the 454 GS Titanium platform (Roche). 


\section{In vitro-positive control for RNA extraction, cDNA synthesis, and pyrosequencing}

The total RNA from $1.0 \mathrm{~mL}$ bacterial culture was extracted using the RNeasy mini kit (Qiagen) according to manufacturer protocols. The MicrobEnrich kit (Ambion) was also used to effect reproducibility of the same experimental steps during in vivo experiments. The total RNA quality was evaluated through on-chip microfluidic electrophoresis as described above. The RNA extracts with RIN $>8$ were considered to be of sequencing quality. This experimental quality control was performed for every RNA extraction attempt from each in vivo technical or biological replicate.

\section{RESULTS AND DISCUSSION}

In our model, the bacterial count reached a mean value of $1.1 \times 10^{9} \mathrm{CFU} / \mathrm{mL}(\mathrm{SD}=$ $3.2 \times 10^{8}$ ), confirming the viability of $B$. fragilis and the suitability of the tissue cage balls for in vivo Bacteroides culture in studies of the host-bacterium relationship. Eukaryotic/prokaryotic cell aggregates were observed (Figure 1e); in addition, the host leukocytes showed a high number of internalized bacteria when compared to the system before experimental infection.
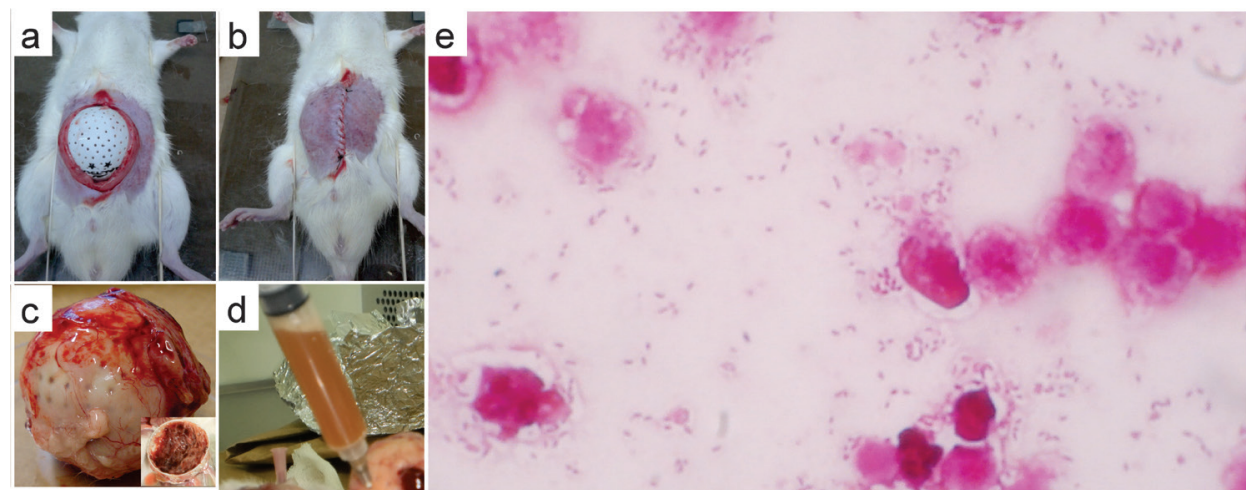

Figure 1. Experimental infection model. Surgical approach used to introduce the table tennis balls into the peritoneal cavity of the study animals $(\mathbf{a}, \mathbf{b})$. Visualization of tissue formation and fluid accumulation in a tissue cage ball (c). Exudate aspirated from a tissue cage ball (d). Representative photomicrograph of the Gram staining of the exudates (e); original magnification, 1000X.

After leukocyte permeabilization, a positive CFU was only found from cells recovered from the infected animals (Figure 2).

Following the first round of pyrosequencing, before any treatment to increase the number of bacterial cells for RNA extraction from the drained exudates, a high number of reads belonging to the rat genome were retrieved at the desired sequencing coverage. These reads overwhelmed those of the $B$. fragilis genome, even after the use of the MicrobEnrich kit (Ambion) to deplete the eukaryotic RNA; the average number of reads related to the eukaryotic genome was 71.924-67.7\%, whereas the respective prokaryotic genome reads represented $34.338-32.3 \%$. At this point, the extracted RNA was of suitable sequencing quality as determined by an RIN $>8$.

To address the issue of low relative prokaryotic yield, Azhikina et al. (2010) proposed a novel experimental approach for studies on host-bacterium interactions. However, 
this method is very laborious, expensive, and can provide biases for the differential expression of genes. Another potential approach is dual RNA-seq. This procedure enables the evaluation of gene expression changes in both the pathogen and the host simultaneously (Westermann et al., 2012). However, as this strategy is also expensive, different treatments were used in this study to reduce the number of eukaryotic cells and thus improve prokaryotic RNA yield. The experimental procedure that consisted of ultrasonic treatment with subsequent centrifugation was found to be the most efficient at increasing yield. As can be observed, bacterial cells showed initially aggregated (Figure 3A and B) and after ultrasonic treatment and centrifugation showed to be more disperse in a high number of individual cells (Figure 3C). Thus, this treatment resulted in a higher number of individual Bacteroides cells (approximately $2.8 \times 10^{9}$ $\mathrm{CFU} / \mathrm{mL}$ ) when compared to centrifugation (Figure 3A) and ultrasonic treatment (Figure 3B) alone, which yielded approximately $6.5 \times 10^{6}$ and $1.4 \times 10^{9} \mathrm{CFU} / \mathrm{mL}$, respectively.

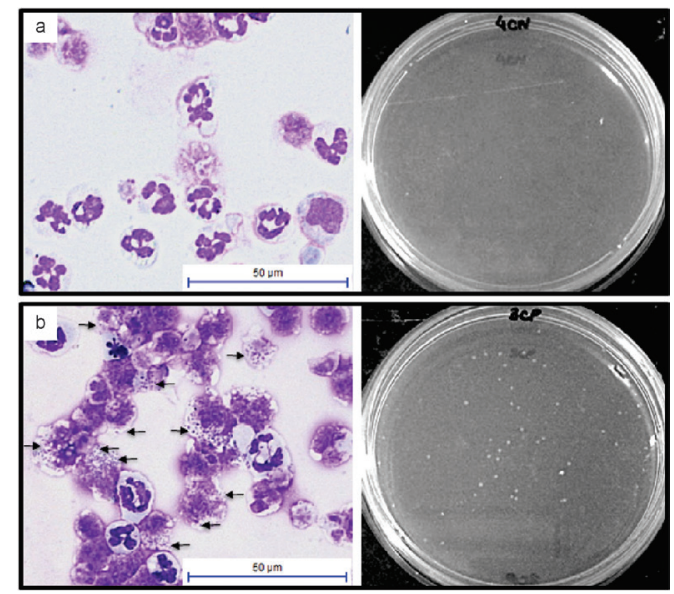

Figure 2. Photomicrographs from leukocytes infected and not infected with Bacteroides fragilis stained with MayGrünwald-Giemsa solution. a. Leukocytes from exudates of non-infected rats. The plate inoculated with exudate shows no bacterial growth after incubation under anaerobic conditions. b. Leukocytes from infected rats. The plate inoculated with exudate shows bacterial growth after incubation under anaerobic conditions. The arrows indicate infected cells.

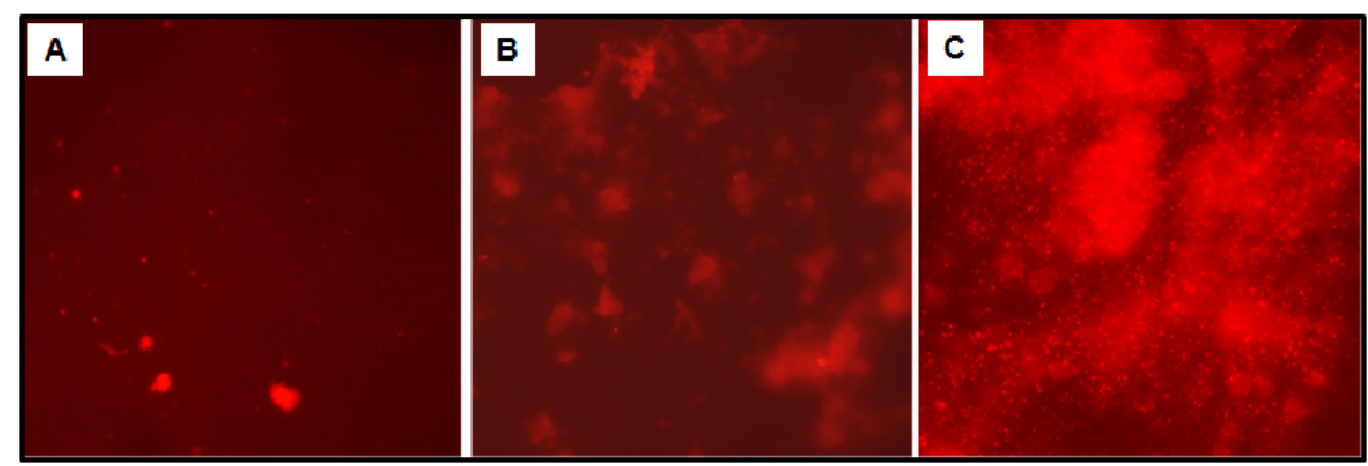

Figure 3. FISH photomicrographs representative of different treatments to improve the yield of prokaryotic cells. A) Centrifugation; B) sonication; and C) both centrifugation and sonication. Original magnification, 1000X. FISH, fluorescence in situ hybridization. 
As observed in this methodological study, the decrease in the eukaryotic cell density was assumed to permit a greater relative yield of prokaryotic DNA/RNA in the final isolated sample. For complex samples such as biological fluids and tissue fragments, the pre-separation of the expected eukaryotic/prokaryotic aggregates will ensure bacterial solubilization and a low eukaryotic contamination. These methodological steps are of extreme importance, especially considering the costs of the high-throughput sequencing technologies that are currently available and which are valuable for use in prospective studies on host-bacterium relationships. However, we found that the most effective exudate treatment (ultrasonic treatment and subsequent centrifugation) was not suitable to obtain high-quality RNA $(\mathrm{RIN}<5.0)$ for further experiments with cDNA synthesis (Figure 4A). This is not entirely unexpected, as it is known that minimal DNA/RNA extract manipulation is advised to avoid mechanical fragmentation or degradation of the nucleotide product. In contrast, the electropherogram representative of in vitro extracts considered as positive controls for RNA purification showed retention of the nucleic acid integrity $(\mathrm{RIN}=8.1)$ (Figure 4B), suggesting that extraction of high-quality total RNA in complex samples might be impaired by the presence of purulent exudate.

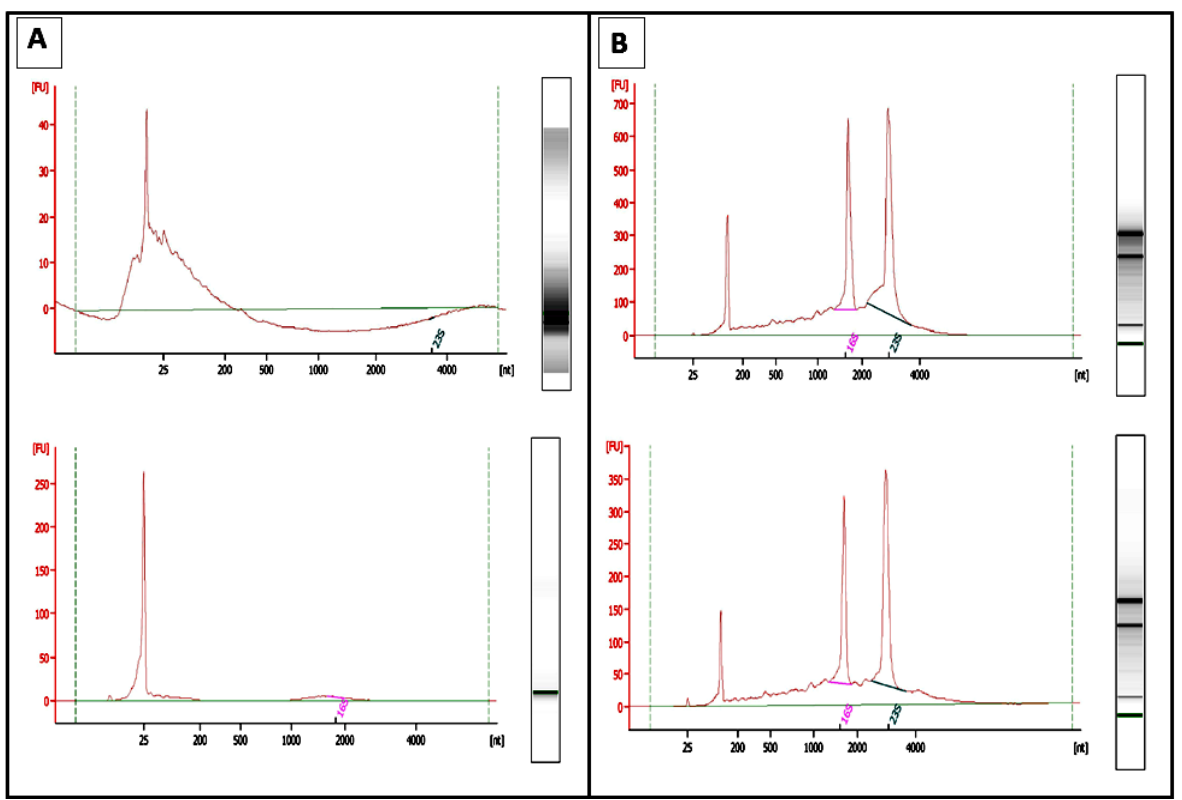

Figure 4. Representative electropherograms used for integrity evaluations of RNA samples extracted after in vivo (A) and in vitro (B) experiments, considering both the biological and technical replicates through on-chip microfluidic electrophoresis. X-axis represents the number of nucleotide (nt) and y-axis represents fluorescence.

In conclusion, we observed that although pretreatment might increase the bacterial RNA yield in this complex sample, such additional laboratory handling might contribute to RNA degradation. Thus, increasing the depth of sequencing might provide an alternative approach to overcome eukaryotic and ribosomal RNA contamination and allow a good retrieval of bacterial transcripts from infected animal tissues. Theoretically, the increased coverage might allow the acquisition of a sufficient number of bacterium reads for subsequent analyses. Despite the high costs, we suggest this strategy to enable in vivo studies of host-bacteria interactions using culture-independent methods. 


\section{Conflicts of interest}

The authors declare no conflict of interest.

\section{ACKNOWLEDGMENTS}

The authors are grateful to the Post-Graduate Program in Biological Sciences (PGCBIO/UFJF). Research supported by Coordenação de Aperfeiçoamento de Pessoal de Nível Superior (CAPES), Fundação de Amparo à Pesquisa de Minas Gerais (FAPEMIG), and Conselho Nacional de Desenvolvimento Científico e Tecnológico (CNPq). The authors are also grateful to Thiago Cesar Nascimento for participating in the animal surgery.

\section{REFERENCES}

Azhikina T, Skvortsov T, Radaeva T, Mardanov A, et al. (2010). A new technique for obtaining whole pathogen transcriptomes from infected host tissues. Biotechinques 48: 139-144.

Bamberger DM, Herndon BL, Fitch J, Florkowski A, et al. (2002). Effects of neutrophils on cefazolin activity and penicillin-binding proteins in Staphylococcus aureus abscesses. Antimicrob. Agents Chemother. 46: 2878-2884.

Brook I (2010). The role of anaerobic bacteria in bacteremia. Anaerobe 16: 183-189.

de Souza Filho JA, Diniz CG, Barbosa NB, de Freitas MC, et al. (2012). Morphological, biochemical, physiological and molecular aspects of the response of Fusobacterium nucleatum exposed to subinhibitory concentrations of antimicrobials. Anaerobe 18: 566-575.

Delsenya M, Hanb B and Hsing Yle (2010). High throughput DNA sequencing: The new sequencing revolution. Plant Sci. 179: 407-422.

Diniz CG, Arantes RM, Cara DC, Lima FL, et al. (2003). Enhanced pathogenicity of susceptible strains of the Bacteroides fragilis group subjected to low doses of metronidazole. Microbes Infect. 5: 19-26.

dos Santos KV, Diniz CG, Veloso LdeC, de Andrade HM, et al. (2010). Proteomic analysis of Escherichia coli with experimentally induced resistance to piperacillin/tazobactam. Res. Microbiol. 161: 268-275.

Lobo LA, Jenkins AL, Smith J and Rocha ER (2013). Expression of Bacteroides fragilis hemolysins in vivo and role of HlyBA in an intra-abdominal infection model. Microbiol. Open 2: 326-337.

Manz W, Amann R, Ludwig W, Vancanneyt M, et al. (1996). Application of a suite of 16S rRNA-specific oligonucleotide probes designed to investigate bacteria of the phylum Cytophaga-Flavobacter-Bacteroides in the natural environment. Microbiology 142: 1097-1106.

Myers LL, Firehammer BD, Shoop DS and Border MM (1984). Bacteroides fragilis: a possible cause of acute diarrheal disease in newborn lambs. Infect. Immun. 44: 241-244.

Myers LL, Shoop DS, Stackhouse LL, Newman FS, et al. (1987). Isolation of enterotoxigenic Bacteroides fragilis from humans with diarrhea. J. Clin. Microbiol. 25: 2330-2333.

Passalacqua KD, Varadarajan A, Ondov BD, Okou DT, et al. (2009). Structure and complexity of a bacterial transcriptome. J. Bacteriol. 191: 3203-3211.

Prindiville TP, Sheikh RA, Cohen SH, Tang YJ, et al. (2000). Bacteroides fragilis enterotoxin gene sequences in patients with inflammatory bowel disease. Emerg. Infect. Dis. 6: 171-174.

Santos SG, Diniz CG, Silva VL, Lima FL, et al. (2012). Differentially regulated proteins in Prevotella intermedia after oxidative stress analyzed by 2D electrophoresis and mass spectrometry. Anaerobe 18: 76-82.

Sîrbu A, Kerr G, Crane M and Ruskin HJ (2012). RNA-seq vs dual- and single-channel microarray data: sensitivity analysis for differential expression and clustering. PLoS One 7: e50986.

Toprak NU, Yagci A, Gulluoglu BM, Akin ML, et al. (2006). Possible role of Bacteroides fragilis enterotoxin in the aetiology of colorectal cancer. Clin. Microbiol. Infect. 12: 782-786.

Westermann AJ, Gorski SA and Vogel J (2012). Dual RNA-seq pathogen and host. Nature Rev. Microbiol. 10: 618-630.

Wexler HM (2007). Bacteroides: the good, the bad, and the nitty-gritty. Clin. Microbiol. Rev. 20: 593-621. 